Productivity and Deregulation in the Canadian For-Hire Trucking Industry, 1985-1996.

Author(s): James Nolan, Pamela Ritchie, and John Rowcraft

Source: Journal of the Transportation Research Forum, Vol. 49, No. 3 (Fall 2010),

pp. 39-52

Published by: Transportation Research Forum

Stable URL: http://www.trforum.org/journal

The Transportation Research Forum, founded in 1958, is an independent, nonprofit organization of transportation professionals who conduct, use, and benefit from research. Its purpose is to provide an impartial meeting ground for carriers, shippers, government officials, consultants, university researchers, suppliers, and others seeking exchange of information and ideas related to both passenger and freight transportation. More information on the Transportation Research Forum can be found on the Web at www.trforum.org. 


\title{
Productivity and Deregulation in the Canadian For-Hire Trucking Industry, 1985-1996
}

\author{
by James Nolan, Pamela Ritchie, and John Rowcraft
}

Many policy makers today take for granted that economic deregulation yields net benefits to industry, particularly with respect to helping improve productivity and efficiency. Certain structural issues about industrial deregulation are not well understood, including the impact of technical change or innovation. In this paper, we measure the extent to which innovation affected productivity within the Canadian for-hire trucking industry during deregulation. Using a unique data set spanning the trucking deregulation era in Canada, non-parametric Malmquist productivity indices are computed and de-composed. Results of the analysis indicate that the industry was affected by deregulation in a manner consistent with public policy goals.

\section{INTRODUCTION}

Policy makers today take for granted the idea that economic deregulation yields net benefits to industry, particularly with respect to helping improve firm level productivity and efficiency. Productivity improvements in deregulated industries can often be attributed to the fact that both incumbents and entrants must seek and implement technological innovations in order to survive and prosper. This paper will illustrate the degree to which innovation plays a part in productivity change in a large, deregulated transportation industry. To achieve this goal, a unique dataset from the Canadian for-hire trucking industry is used to compute a non-parametric industry level productivity index through the time of deregulation. This index is subsequently decomposed to identify the sources of productivity change in the industry.

Transportation is a vital component of the Canadian economy, and by value, trucking continues to be the most important commercial mode of transportation. As an industry, trucking can be separated into two primary sectors. These are i) the private sector, where trucking happens to be an integrated part of firm activity, and ii) the for-hire sector, comprised exclusively of carriers who only provide transportation services. These sectors are not mutually exclusive; large shippers often use both private and for-hire carriers to provide transportation services (Wood and Johnson 1996). Whereas private trucking accounts for slightly more total transportation activity than for-hire trucking in Canada, the for-hire sector is still critical to the economy. While total trucking movement in Canada roughly tripled from 1987 to 1997 (Transport Canada 1999), for-hire trucking grew at a remarkable rate after deregulation. In the decade following deregulation, total for-hire trucking revenues doubled, while approximately $14 \%$ of for-hire trucking firms had revenues in excess of $\$ 1$ million per year (Nix 1996).

The following section contains a brief institutional and historical review of the Canadian trucking industry. Then the relationship between regulation and productivity is described. A brief descriptive theory section highlights why productivity changes are crucial to the study of deregulation. Next, a detailed account of the methodology used in the study is presented. After a discussion of the empirical results, a brief set of conclusions ends the paper.

\section{REGULATION AND THE TRUCKING INDUSTRY IN CANADA}

The development and evolution of the Canadian for-hire trucking industry relates closely to its counterpart in the United States. The industry in each country conducts much of its operations as 
part of the complete North American market. From a regulatory perspective, they have been treated historically in a similar manner by their respective governments.

The policy of economic regulation in the U.S. trucking industry, which took the form of entry restrictions and rate setting, began as far back as the 1930s. Political pressure from rail interests forced increased regulation of the trucking industry because the rail freight industry was itself heavily regulated at that time. Thus, some authors have concluded that the U.S. trucking industry was regulated solely in the interest of creating a "level playing field" for all firms and modes operating in the freight transportation market (Viscusi et al. 1996).

Trucking regulation in Canada was also implemented as a response to pressure from the regulated Canadian rail companies, but similar regulatory policies also permitted easier access to the important U.S. freight market (Woudsma and Kanaroglou 1994). In both countries, the primary impetus for regulating the for-hire trucking industry was not due to typical market problems like excessive concentration or conditions of natural monopoly. In spite of this unusual situation, regulatory policy towards the trucking industry in Canada and the United States remained unchanged for almost 50 years.

Economic regulation in the Canadian trucking industry most often took the form of restrictions on entry by new firms (Bonsor 1995). Certain special freight rates were also pre-determined by regulatory fiat. This prolonged policy of regulatory protection of almost every trucking market against entry certainly weakened incentives for firms to innovate in the provision of trucking services. ${ }^{1}$ But by 1980 , once the U.S. rail industry had been partially deregulated, the U.S. trucking industry was fully deregulated as well. Subsequently, the trucking industry in Canada followed suit through the early 1980s. ${ }^{2}$ By 1988, domestic trucking markets and routes in Canada were no longer protected by law against entry (Dionne et al. 1998). Most analysts agree that by 1993, for-hire trucking deregulation in Canada was complete.

In the years since deregulation, the Canadian trucking industry has continued to undergo substantial change. By way of example, 38 of the top 100 trucking companies (measured by total revenues) operating in 1990 were no longer operating by 1995, most often transformed or subsumed through buy-outs or mergers. ${ }^{3,4}$ But evidence from the latter part of this sample shows that the importance of larger carriers in the industry declined, and the for-hire industry itself became less concentrated after deregulation (Transport Canada 1996). However, some industry observers believe that for-hire trucking deregulation in Canada has been characterized by extreme instability in prices and output (Nix 1996). In summary, it can be very difficult to judge the merits of deregulation by simple indicators of market performance. In fact, the very nature of the delivered good in trucking has changed due to several major technological changes that occurred during deregulation.

The most obvious example of technological change in the trucking industry is the development and use of satellite/Global Positioning System (GPS) tracking systems, begun in the late 1980s. Among the largest carriers in particular, GPS has replaced short-range dispatch systems to ensure that delivery occurs when and where desired. The spread of this particular innovation has been driven by increased use of just-in-time logistics with precise delivery windows. Without a doubt, innovations of this sort have substantially altered the freight transportation industry, both rail and trucking, throughout North America.

If we define productivity as the ability of a firm to produce outputs from a given set of inputs over time, then policy shocks such as deregulation affect productivity at the industry level by changing behavior at the firm level. In this research, the following questions are addressed: i) Are industry level productivity changes through a transition to deregulation different from those that can be expected to occur in a regulated industry, and ii) in what manner has this particular industry reacted to the process of deregulation? In the next section, the first question is addressed along with a description of how productivity changes within an industry constitute a litmus test as to the "appropriateness" of deregulation for the industry. 


\section{DEREGULATION AND PRODUCTIVITY}

Trucking companies in Canada did not need to be particularly innovative or even economically efficient in order to survive in the regulatory era. Heavy-handed and long-term regulation in Canada meant that trucking firms possessed few incentives to innovate in order to gain competitive advantage (Viscusi et al. 1996). As might be expected of firms under such regulation, there is strong evidence in Canada that considerable resources were devoted to entry seeking and forestalling (Bonsor 1995).

The fact that this industry survived under such conditions does not imply that firms were productively efficient in an absolute sense. But without loss of generality, it can be assumed that as the regulatory era drew to a close, the largest Canadian for-hire trucking firms operated with similar levels of productive efficiency. This was simply due to the fact that throughout the era of regulation, trucking companies had plenty of time to discover those procedures and processes required to efficiently produce output within the constraints (for example, inflexible route structures and rates) inherent in the regulatory regime.

Under these conditions, it is likely that a relative lack of innovation in production technology existed in the regulated Canadian trucking industry compared with what would have been the case under a competitive environment characterized by frequent entry and exit of firms. Without foreseeable changes in market risk or profit levels, trucking firms in Canada maintained the status quo with respect to industry structure. Such a stylized description of events also implies that the "best practice" technology in regulated for-hire trucking was well established and that all firms producing the same services would likely employ similar technologies. Thus, by the time of deregulation, forhire trucking was a mature industry in Canada characterized by stable prices and output levels with few differences among the operating procedures of firms.

Now consider the nature of productivity changes in this regulated industry. In the prolonged period prior to regulatory change, it is very likely that the dominant component of temporal productivity change for any individual trucking firm consisted of emulating those technological processes that were already well established. In the productivity measurement literature, this type of productivity change is referred to as a change in technical efficiency (Lovell 1993). More formally, the technical efficiency effect is defined simply as a change in efficiency relative to a static industry production possibility frontier.

Economists assert that industrial deregulation generates numerous benefits. But aside from demand side considerations, many authors argue it is extremely important that open entry also stimulate technical innovation in industry (Scherer and Ross 1990; Gallamore 1999). Therefore in contrast to the situation that is argued to exist under prolonged regulation, it can be argued that changes in productivity over time through the period of deregulation are dominated (at least) initially by shifts in technology. This is known as technical change in the productivity literature. As opposed to the technical efficiency effect, technical change is defined as a shift in the level of best practice technology represented by the industry production possibility frontier. Among incumbent firms in the industry, those that survive the shock of deregulation will do so because they innovate and adapt to the new market situation. ${ }^{5}$

Using these basic arguments as a foundation for evaluating the merits of de-regulation, sources of year-to-year productivity change among the largest firms in the Canadian trucking industry during the window of deregulation are identified by computing and decomposing a non-parametric Malmquist productivity index for these firms. To the best of our knowledge the Canadian data employed here are novel, but the methodology mirrors the work of McMullen and Okuyama (2000) measuring and interpreting productivity changes in the U.S. trucking sector.

\section{THE MEASUREMENT OF TECHNICAL EFFICIENCY AND PRODUCTIVITY}

To evaluate non-parametric productivity changes in the Canadian for-hire trucking industry, static technical efficiency is measured using data envelopment analysis (DEA). DEA is a non-parametric 
efficiency estimation methodology consisting of a series of specially configured linear programs. DEA is a useful analytic tool to measure efficiency because it does not require any prior assumptions about the structure of production technology in the industry. This flexibility is important if the researcher is somewhat ignorant about the structural nature of the production technology in question (Seiford and Thrall 1990). It would be imprudent to make any a priori assumptions about the structure of technology in this industry, especially considering the significant technological changes that most certainly occurred during and after deregulation.

In this paper, output oriented DEA scores are computed. Output-oriented DEA generates a hypothetical measure of how much a firm's outputs could have been proportionately increased, with inputs held fixed, such that it transformed inputs into outputs as efficiently as the best firms in the sample. Thus, output oriented DEA efficiency scores fall in a range between 1 and infinity, where an efficiency score of 1 means that the firm is technically efficient (or equivalently, the datum falls on the production possibility frontier). An efficiency score greater than 1 indicates that a firm could theoretically increase outputs by a factor of \{efficiency score - 1$\}$ percent to produce as efficiently as the best practice firms in the sample. The linear program used to compute the efficiency scores (the basic output oriented, constant returns to scale version of DEA) is the following:

$$
\begin{array}{rc}
\text { Min }_{\text {u,v }} & v \mathrm{X}_{1} \\
\text { s.t. } & \mu \mathrm{Y}_{1}=1 \\
& -\mu \mathrm{Y}+v \mathrm{X} \geq 0 \\
& \mu \geq 0, v \geq 0
\end{array}
$$

Here, $\mathrm{Y}$ and $\mathrm{X}$ in the second constraint in (1) represent vectors of outputs and inputs respectively across the entire sample, whereas $X_{1}$ and $Y_{1}$ are those inputs and outputs unique to the particular firm under examination. Also, $\mu$ and $v$ are vectors of so-called "virtual" multipliers, and are coefficients necessary to solve the linear program. ${ }^{6}$ The linear program is solved once for each observation in the sample (with the non-negativity and second constraint in (1) being common to each LP) and yields the technical efficiency measure for each firm.

By definition, the reference data set of firms used to calculate the relative efficiency scores (represented by the second constraint in (1)) consists of all other firms operating in the same time period. Therefore, the level of industry technology in a given year is defined exclusively by firms in the dataset at that time, and not on a theoretical level dependent upon a chosen functional form of production.

Table 4 shows the average DEA scores for all trucking firms in the sample spanning 1985-1997. The average scores fluctuate somewhat over time, as might be expected given the policy changes in the industry. Note that the highest (least average efficiency) score occurs in 1994 and the lowest (highest average efficiency) occurs in 1997. These efficiency scores are subsequently used as inputs into the computation of the productivity indices.

\section{THE MALMQUIST INDEX}

The productivity index used in this paper is the Malmquist index. The index facilitates identification of temporal sources (or components) of productivity change. These components are: i) technical efficiency, or the convergence of technology among the firms in the sample over time towards the best practice frontier, and ii) technical change, or shifts in the production frontier due to changes in the overall level of technology used by firms in the industry.

In terms of the technical efficiency scores computed with DEA, the Malmquist index can be written in the following manner (Lovell 1993): 
(2) $M_{0}^{t+1}\left(x^{t+1}, y^{t+1}, x^{t}, y^{t}\right)=\left[\frac{D_{0}^{t}\left(x^{t+1}, y^{t+1}\right)}{D_{0}^{t}\left(x^{t}, y^{t}\right)} \frac{D_{0}^{t+1}\left(x^{t+1}, y^{t+1}\right)}{D_{0}^{t+1}\left(x^{t}, y^{t}\right)}\right]^{1 / 2}$

And this equation can be decomposed into the following components:

(3) $\left.M_{0}^{t+1} x^{t+1}, y^{t+1}, x^{t}, y^{t}\right)=\frac{D_{0}^{t+1}\left(x^{t+1}, y^{t+1}\right)}{D_{0}^{t}\left(x^{t}, y^{t}\right)}\left[\frac{D_{0}^{t}\left(x^{t+1}, y^{t+1}\right)}{D_{0}^{t+1}\left(x^{t+1}, y^{t+1}\right)} \frac{D_{0}^{t}\left(x^{t}, y^{t}\right)}{D_{0}^{t+1}\left(x^{t}, y^{t}\right)}\right]^{1 / 2}$

In this notation, $\mathrm{D}_{\mathrm{o}}$ is a standard output distance function (Shephard 1953), which is simply the inverse of the output oriented DEA technical efficiency scores. This allows for a straightforward computation of the Malmquist index under the chosen DEA specification. The superscripts on $\mathrm{D}_{\mathrm{o}}$ indicate the reference time period (or technology) with which the scores are calculated. The superscripts on $\mathbf{x}$ (inputs) and $\mathbf{y}$ (outputs) indicate the time period of the data used in the index calculation. For example, if the superscripts for each distance function are the same, the efficiency score is calculated in the standard way using the data of other firms operating in the same time period. However, if the superscripts in the distance functions are not the same (i.e., $t$ vs. $t+1$ ), the DEA efficiency score for an observation is computed instead by using, as the reference set, industry data from the adjacent time period.

The first term on the right-hand side in equation (3) measures the change in technical efficiency between time periods, or the change in the DEA score from period $t$ to period $t+1$. The second term measures pure technical change over time by computing modified DEA scores for a given firm in a particular year relative to the technology sets (the data on inputs and outputs) of both the previous $\left(\mathrm{D}_{\mathrm{o}}^{\mathrm{t}}\left(\mathrm{x}^{\mathrm{t}+1}, \mathrm{y}^{\mathrm{t}+1}\right)\right)$ and succeeding $\left(\left(\mathrm{D}_{\mathrm{o}}^{\mathrm{t}+1}\left(\mathrm{x}^{\mathrm{t}}, \mathrm{y}^{\mathrm{t}}\right)\right)\right.$ years.

Intuitively, the Malmquist index compares the level of industry technology in the current year with those from previous and future years. The changes in the technical efficiency scores induced by changing the reference technology set are used to examine whether or not individual firms contribute either to the shifting of the production possibility frontier, or if firms are simply "catching up" with the prevailing level of technology.

As in McMullen and Okuyama (2000), the decomposition of the industry Malmquist index will be interpreted in the following manner. The technical efficiency term is called the "catching up" term (see also Fare et al. 1994), and measures the effect on productivity of firms catching up to the performance of the most efficient firms in the sample.

This term:

- $\quad$ equals 1 when no change in technical efficiency has occurred;

- $\quad$ is less than 1 when technical efficiency has declined over time;

- $\quad$ is greater than 1 when technical efficiency has increased over time.

The second term in the Malmquist decomposition is often referred to as the technical change or "innovation" term, measuring how much overall productivity change is due to the efficiency frontier shifting from one time period to the next. If this term dominates the index, the level of best practice technology in the industry has changed and the best performing firms in the industry became more efficient. This term:

- $\quad$ equals 1 when no technical change has occurred;

- $\quad$ is less than 1 when there has been regressive technical change;

- $\quad$ is greater than 1 when there has been progressive technical change.

The Malmquist index itself is interpreted in the same manner as the individual terms. Thus the index:

- equals 1 when no change in productivity has occurred;

- is less than 1 when productivity has declined over time;

- $\quad$ is greater than 1 when productivity has increased over time. 
By using this decomposition, the structure of productivity changes among this set of firms during deregulation in the Canadian for-hire trucking industry can be identified. And since average indices of productivity and decompositions are computed, the results can be interpreted with respect to the entire sample on aggregate.

\section{DATA}

The sample comprises a set of the largest for-hire trucking firms operating across Canada. ${ }^{7}$ The data were compiled from several sources, including the Motor Carriers of Freight (MCF) survey conducted by Statistics Canada (1993). ${ }^{8}$ Even though there are more Class I firms in Canada (about 350 in 1993) than in the sample, only about one-third of these firms were actually surveyed in any given year (Statistics Canada 1993). The sub-sample consists of those firms for which reliable data were available from the MCF survey through the entire period of trucking deregulation. ${ }^{9}$

The empirical analysis is composed of two parts. First, DEA scores and Malmquist indices are computed using a balanced panel of 14 trucking firms over 12 years, from 1985 to 1996. Balanced panels are best employed in the computation of Malmquist indices so that reference technology sets do not change; this ensures consistency of the results between specific firms (Lovell 1993). But since only overall productivity results are of interest here and not results at the firm level, such consistency is not as critical. Subsequently, the second portion of this study computes Malmquist indices for a slightly larger unbalanced panel of 21 firms over 13 years, from 1985-1997. See Table 1 for a comparison of sample sizes for the balanced and unbalanced panels.

Table 1: Sample Sizes Used for the Balanced and Unbalanced Panels

\begin{tabular}{l|c|c|c|c|c|c|c|c|c|c|c|c|c}
\hline Year & $\mathbf{8 5}$ & $\mathbf{8 6}$ & $\mathbf{8 7}$ & $\mathbf{8 8}$ & $\mathbf{8 9}$ & $\mathbf{9 0}$ & $\mathbf{9 1}$ & $\mathbf{9 2}$ & $\mathbf{9 3}$ & $\mathbf{9 4}$ & $\mathbf{9 5}$ & $\mathbf{9 6}$ & $\mathbf{9 7}$ \\
\hline Balanced & 12 & 12 & 12 & 12 & 12 & 12 & 12 & 12 & 12 & 12 & 12 & 12 & - \\
\cline { 2 - 37 } & 19 & 19 & 19 & 20 & 20 & 19 & 20 & 20 & 20 & 17 & 18 & 18 & 15 \\
\hline
\end{tabular}

Table 2 provides summary statistics for the input and output variables for the full (unbalanced) sample, whereas Table 3 provides the summary statistics for the balanced panel estimates. With respect to variable selection, non-parametric studies of productivity and efficiency of transportation modes have used similar variables to those chosen here (Bookbinder and Qu 1993; McMullen and Okuyama 2000). This set of input and output variables constitutes a parsimonious but reasonable representation of the structure of production in the trucking industry.

Table 2: Full (Unbalanced) Sample Descriptive Statistics, 1985-1997

\begin{tabular}{|c|c|c|c|}
\hline Inputs & $\begin{array}{c}\text { Number of } \\
\text { employees }\end{array}$ & Total vehicles & $\begin{array}{c}\text { Fuel Consumption } \\
\text { (liters) }\end{array}$ \\
\hline Mean & 668.87 & $1,010.84$ & $9,883,616.59$ \\
S.D. & 53.54 & 71.03 & $607,683.97$ \\
Max & 5,906 & 7,666 & $53,388,743$ \\
Min & 49 & 25 & 111,810 \\
\hline Outputs & Total number of & Tonne-Kilometers & \\
\hline Mean & $457,771.78$ & $508,692,461.9$ & \\
S.D. & $34,143.24$ & $28,701,722.58$ & \\
Max & $2,607,683$ & $2,469,461,919$ & \\
Min & 4,246 & $1,177,340$ & \\
\cline { 1 - 2 } & \multicolumn{2}{|c}{}
\end{tabular}


Table 3: Balanced Sample Descriptive Statistics, 1985-1996

\begin{tabular}{|c|c|c|c|}
\hline Inputs & Number of employees & Total vehicles & $\begin{array}{c}\text { Fuel Consumption } \\
\text { (liters) }\end{array}$ \\
\hline Mean & 727.56 & $1,072.84$ & $10,690,223.04$ \\
S.D. & 84.16 & 104.54 & $852,775.41$ \\
Max & 5,906 & 7,666 & $53,388,743$ \\
Min & 112 & 155 & $1,015,000$ \\
\hline Outputs & Total number of & Tonne-Kilometers & \\
\cline { 1 - 2 } Mean & shipments & $544,778,399.4$ & \\
S.D. & $430,460.62$ & $38,492,130.47$ & \\
Max & $41,599.41$ & $2,469,461,919$ & \\
Min & $2,412,023$ & $4,796,814$ & \\
\cline { 1 - 2 } & 5,001 & \multicolumn{2}{|c}{}
\end{tabular}

Some size discrepancies among the firms in the sample open the possibility that not all of these firms are operating at constant returns to scale, and the assumption of CRS facilitates the computation of Malmquist indices (Lovell 1993). However, parametric studies of the U.S. trucking industry offer a strong consensus that the for-hire industry operates at constant returns to scale (Braeutigam 1999). Given the large number of firms operating in the Canadian for-hire trucking industry (over 8,000 operators of all sizes as of 1993; Nix 1996), it is likely that post-deregulation trucking technology operates effectively at constant returns to scale. Furthermore, it is very unlikely that this sample of large companies includes any firms operating at increasing returns to scale. Therefore, the constant returns to scale formulation used to compute the DEA efficiency scores and the Malmquist indices seem to be a reasonable assumption for this analysis.

Table 4: Average DEA Scores, All Firms, Full Sample (1985-1997)

\begin{tabular}{cc|cc}
\hline Year & CRS DEA Score & Year & CRS DEA Score \\
\hline 1985 & 1.22 & 1992 & 1.09 \\
1986 & 1.11 & 1993 & 1.10 \\
1987 & 1.16 & 1994 & 1.37 \\
1988 & 1.21 & 1995 & 1.08 \\
1989 & 1.15 & 1996 & 1.28 \\
1990 & 1.22 & 1997 & 1.02 \\
1991 & 1.09 & & \\
\hline
\end{tabular}

As a final point about the data, there is no way to directly control for provincial regulatory differences because in order to obtain a reasonable sample size, the data necessarily include firms operating all over Canada. ${ }^{10}$ After the process of trucking deregulation began, provinces continued to exert varying levels of control over certain aspects of the industry, particularly safety (Nix 1996). But entry and rate deregulation of trucking was mandated from the federal level and therefore, was relatively homogenous across the country. Therefore, it is safe to assume that any regulatory variability found from province to province will not affect the basic results obtained here. 


\section{RESULTS AND INTERPRETATION}

Table 5 shows the average of the Malmquist index for each year computed with both the balanced and unbalanced panels of data. Table 6 and Figure 1 show the average of the two productivity components and the Malmquist indices for all firms computed with the balanced panel sample. Since the Malmquist productivity indices are calculated year to year, the productivity gains observed in a given year are relative to productivity levels in the previous year only.

As a test of data sensitivity, the full (unbalanced) sample was used to calculate another series of averaged Malmquist indices and components. These are shown in Figure 2 and Tables 5 and 6. Overall, industry productivity increases steadily over time in the sample (Table 5). Both sets of indices (balanced and unbalanced) show increases in overall productivity from 1986-1988. The effects of the 1990-91 recession can be seen as well in Figures 1 and 2, with productivity slipping in both samples. In fact, this recession hit the trucking industry particularly hard (Nix 1996). Finally, another noticeable increase in productivity appears starting 1994-1995, diminishing slightly towards the end of this sample.

Table 5: Malmquist Average Scores for All Firms, Both Samples (1985-1997)

\begin{tabular}{cccccc}
\hline Year & $\begin{array}{c}\text { Index, } \\
\text { balanced } \\
\text { sample }\end{array}$ & $\begin{array}{c}\text { Index, } \\
\text { unbalanced } \\
\text { sample }\end{array}$ & Year & $\begin{array}{c}\text { Index, } \\
\text { balanced } \\
\text { sample }\end{array}$ & $\begin{array}{c}\text { Index, } \\
\text { unbalanced } \\
\text { sample }\end{array}$ \\
\hline 1986 & 1.14 & 1.09 & 1992 & 1.08 & 1.23 \\
1987 & 1.65 & 1.36 & 1993 & 1.12 & 1.17 \\
1988 & 2.80 & 1.49 & 1994 & 0.89 & 0.72 \\
1989 & 1.06 & 0.98 & 1995 & 1.28 & 1.58 \\
1990 & 1.01 & 0.83 & 1996 & 1.63 & 1.02 \\
1991 & 1.03 & 0.98 & 1997 & - & 1.10 \\
\hline
\end{tabular}

Table 6: Average Malmquist De-composition Components, Both Samples

\begin{tabular}{ccc|ccc}
\hline \multicolumn{3}{c|}{ Balanced Sample } & \multicolumn{3}{c}{ Unbalanced Sample } \\
\hline Year & $\begin{array}{c}\text { Technical } \\
\text { Efficiency }\end{array}$ & $\begin{array}{c}\text { Technical } \\
\text { Change }\end{array}$ & Year & $\begin{array}{c}\text { Technical } \\
\text { Efficiency }\end{array}$ & $\begin{array}{c}\text { Technical } \\
\text { Change }\end{array}$ \\
\hline 1986 & 1.14 & 1.00 & 1986 & 1.09 & 1.01 \\
1987 & 1.27 & 1.28 & 1987 & 0.97 & 1.42 \\
1988 & 0.64 & 4.83 & 1988 & 0.97 & 1.60 \\
1989 & 4.17 & 0.30 & 1989 & 1.07 & 0.94 \\
1990 & 0.98 & 1.01 & 1990 & 0.98 & 0.86 \\
1991 & 1.06 & 0.95 & 1991 & 1.12 & 0.90 \\
1992 & 0.97 & 1.12 & 1992 & 1.00 & 1.23 \\
1993 & 1.05 & 1.07 & 1993 & 0.99 & 1.18 \\
1994 & 1.00 & 0.89 & 1994 & 0.91 & 0.83 \\
1995 & 0.90 & 1.41 & 1995 & 1.35 & 1.22 \\
1996 & 1.32 & 1.18 & 1996 & 0.93 & 1.21 \\
1997 & - & - & 1997 & 1.24 & 0.95 \\
\hline
\end{tabular}


Figure 1: Balanced Sample Malmquist Productivity De-composition, 1985-1996 (vertical axis is the index value)

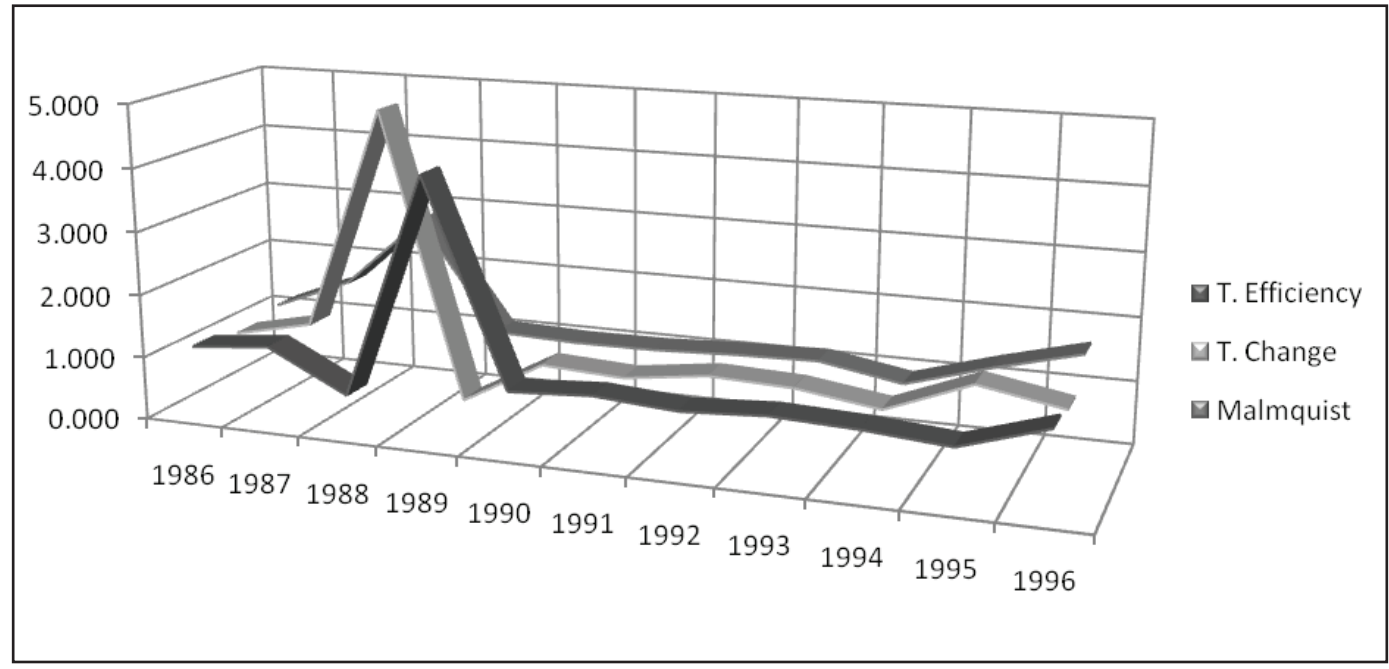

Figure 2: Full (Unbalanced) Sample Malmquist Productivity De-composition, 1985-1997 (vertical axis is the index value)

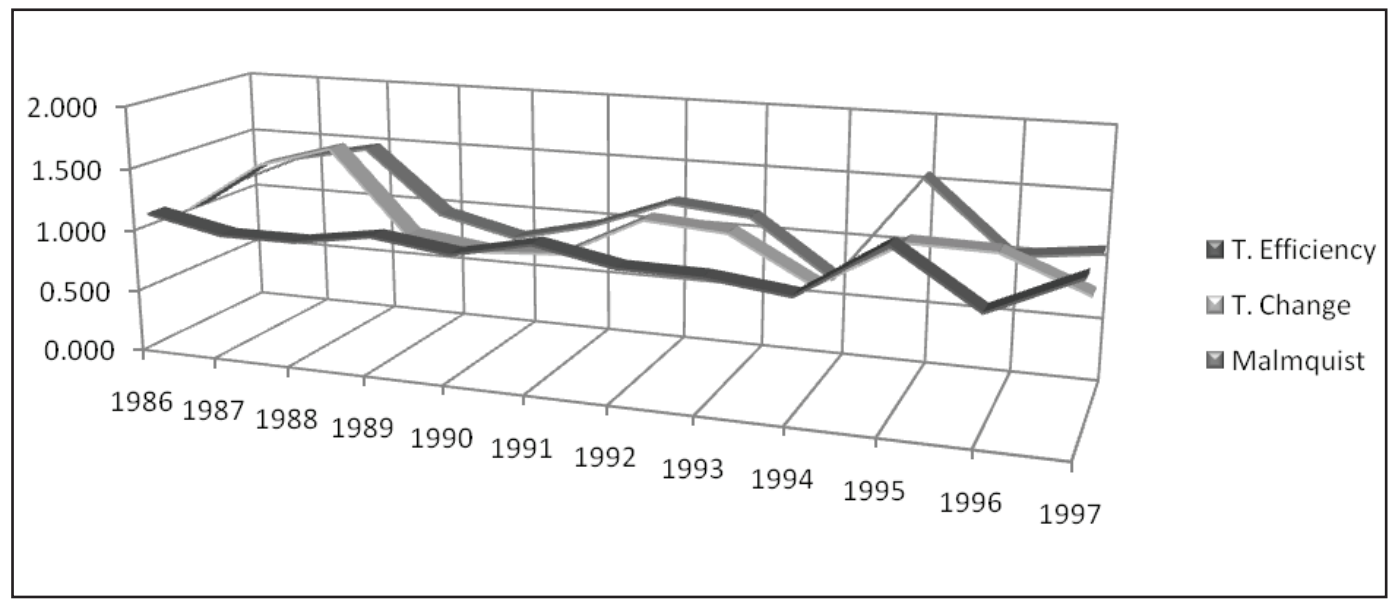

The index de-compositions indicate that the technical change or innovation term dominates the Malmquist index over most of the sample, and especially in the initial period following deregulation. To help identify relationships between productivity and innovation in the data, sample correlations and a Spearman non-parametric rank test (for independence) between the Malmquist index and the de-composed terms were performed. One reason for computing the Spearman rank statistic is that as a non-parametric test, it allows a more general assessment of the relationship between the non-parametric Malmquist index and its components. The Spearman statistic indicates which of the decomposition factors is more critical to the calculation of the index. Both the sample correlations and the Spearman rank tests are shown in Table 7. 
Table 7: Malmquist Component Correlations with the Malmquist Index

\begin{tabular}{|c|c|c|c|c|}
\hline $\begin{array}{c}\text { Balanced Panel } \\
\text { 1985-1996 }\end{array}$ & Entire Sample & 1988-1993 & 1994-1996 & $\begin{array}{l}\text { Spearman test of } \\
\text { Independence } \\
\text { (entire sample)* }\end{array}$ \\
\hline Technical Change & 0.923 & 0.983 & 0.586 & $\begin{array}{c}\rho=0.8273 \\
(0.0017)\end{array}$ \\
\hline Technical Efficiency & -0.242 & -0.311 & 0.698 & $\begin{array}{c}\rho=-0.0364 \\
(0.915)\end{array}$ \\
\hline $\begin{array}{c}\text { Unbalanced Panel } \\
\text { 1985-1997 }\end{array}$ & Entire Sample & 1988-1993 & 1994-1997 & $\begin{array}{l}\text { Spearman test of } \\
\text { Independence } \\
\text { (entire sample) }\end{array}$ \\
\hline Technical Change & 0.830 & 0.984 & 0.735 & $\begin{array}{c}\rho=0.9021 \\
(0.0001)\end{array}$ \\
\hline Technical Efficiency & 0.406 & -0.468 & 0.868 & $\begin{array}{c}\rho=0.2657 \\
(0.4038)\end{array}$ \\
\hline
\end{tabular}

* The corresponding P-value is listed under each test statistic in brackets.

For both Malmquist indices (balanced and unbalanced), the full sample correlation between the technical change term and the index was extremely high (over 0.8 in both cases), exceeding the measured correlation associated with the technical efficiency term. In addition, in both samples the technical change term is significantly correlated with the Malmquist index (i.e., the null hypothesis of independence between the data series is strongly rejected).

Conversely, the technical efficiency term is found to be statistically independent of the Malmquist index in both samples (i.e., we cannot reject the null hypothesis of independence), although weakly so in the unbalanced panel (P-value $=0.40)$. But overall, the statistical evidence presented here shows that the technical change or innovation term tended to dominate productivity change in both samples. However, variability in the values of each de-composition component across the sample (see Table 6) indicated that specific periods of interest needed closer examination.

The sample was split into two crucial periods in these initial stages of Canadian trucking deregulation: i) the immediate post deregulation period from 1988-1993; and ii) the latter stages of the deregulation process from 1994-1996. Malmquist correlations in Table 7 show that productivity change at the beginning of the deregulation era was dominated by technical change or innovation. For instance, the technical change term drives the productivity index up to 1993 (with correlations of 0.983 [balanced sample] and 0.984 [unbalanced sample]). This finding is consistent with consensus about the time it took for the industry to adjust to the deregulation transition (Dionne et al. 1998). But the correlations in Table 7 also show that by 1994, the process of innovation driving productivity improvements was slowing. As time progressed, it is clear that the "catching up" or technical efficiency term eventually became the driver (i.e., there is a higher correlation between the technical efficiency term and the productivity indices from 1994-1996 than from 1988-1993 within both samples) behind productivity changes in the Canadian for-hire trucking industry. Thus, the Malmquist index decomposition confirms that innovation among the largest for-hire trucking firms in Canada slowed over time after initial de-regulation, with subsequent productivity changes realized instead through the emulation of extant best practices or technology.

It must be noted that in contrast to these Canadian findings, McMullen and Okuyama (2000) performed a similar analysis on trucking and found that technical change in the early U.S. postderegulation period declined. The industries in each country are quite similar and there was no evidence of any fundamental differences between the two industries at the time of de-regulation (Bonsor 1995). In this light, one explanation for the observed difference in technical change that 
is consistent with the interpretation above is that most of the large Canadian for-hire carriers in fact served markets throughout all of North America. The deregulation of U.S. trucking markets predated Canadian deregulation. Adjustments to U.S. policy changes may have induced certain operational changes among the Canadian carriers in this sample, including the need to improve their technical efficiency in order to better compete in the liberalized U.S. market. And while of potential interest, identifying the exact source of the changes in technical efficiency in Canada is beyond the scope of this study.

\section{CONCLUSION}

A unique Canadian dataset is used to examine the relationship between productivity and the process of deregulation in the for-hire trucking industry. This research adds to the growing body of empirical work concerning the nature of firm behavior by decomposing a Malmquist productivity index computed through the time of economic deregulation in this industry.

One desirable consequence of economic deregulation is that after implementation, firms will act upon a set of new incentives and ultimately compete by innovating. We identified such an effect within the early stages of trucking deregulation in Canada. It was also found that innovation in the industry ultimately declined over time, likely as a result of firms adjusting to the new regulatory environment by emulating extant technology rather than continuing to pursue innovation. Analyzing whether or not productivity improvements in Canadian for-hire trucking attributable to innovation simply fade after the act of deregulation or are cyclical in nature awaits further data. An extension in this direction would clearly contribute to the extensive and growing literature on innovation and industry life cycles (see for example, Cefis and Marsili 2005).

Events of the past two decades have shown that technology improvements often occur in ways that were unforeseen before changes in economic regulation (Winston 1993). Sometimes an unforeseen technical change is obvious to the casual observer, such as the ubiquitous advent of satellite tracking systems, but in other cases technical improvements and their consequences are more subtle. It is in the latter cases in which the methodology and interpretation implemented here would help measure and identify changes in firm behavior brought about by deregulation. Ideally, it would be instructive to compare these findings with those from industries that have undergone a similar regulatory transition and examine whether differences exist across productivity de-compositions.

\section{Endnotes}

1. See Viscusi et al. (1996) for a detailed overview of regulation and its effects on the U.S. trucking industry. The history and evolution of trucking regulation in Canada is similar.

2. The Canadian provinces enforced various forms of their own economic regulation, but federal level deregulation was seen as a crucial step to improving competition in this industry.

3. Since the focus in this research is on the behavior of the largest (Class 1) carriers, the total sample size is limited. This increases the risk of "survivor bias" over the sample (especially in the balanced sample) since these firms remained intact throughout the duration of the regulatory transition. But such bias is not likely to be an issue since the point of the research is to examine those firms who survived the shock of deregulation.

4. Through the sample period, alliances were becoming increasingly important to Canadian carriers looking to expand service into the United States (Transport Canada 1996).

5. On a theoretical note, this discussion implicitly assumes that potential property rights enforcement issues in innovation did not hinder deregulation. Those innovations that became popular in this segment of trucking (e.g., hub and spoke networking, GPS based logistics) 
were commonly known in the industry and clearly part of the public domain around the time of trucking deregulation in Canada. This is not to say that property rights issues in innovation will never become important in trucking, only that these issues do not affect the results from the period under analysis.

6. Microsoft Excel Solver was used to compute both the efficiency scores and the Malmquist indices.

7. Class 1 trucking firms were defined in Canada as those firms earning more than C $\$ 5$ million in revenue per year. This classification was changed in 1996, but the old classification is relevant to the data used here.

8. Some of the data used here are also described in Nolan (1998). The authors would like to also thank R. Laroque at Statistics Canada for compiling much of this dataset.

9. We have made every effort to ensure that the firms in the sample do not rely upon "owneroperators," the use of which could affect the reported inputs for the firm, depending on how the firm chooses to report operating data to Statistics Canada.

10. The data used are confidential, so identifying individual firms is not possible. However, both samples were examined to ensure that they did not include merged firms.

\section{References}

Bonsor, N. "Competition, Regulation and Efficiency in the Canadian Railway and Highway Industries." Filip Palda, ed. Essays in Canadian Surface Transportation. Vancouver, B.C.: The Fraser Institute (1995): Ch.2.

Bookbinder, J.H. and W.W. Qu. “Comparing the Performance of Major American Railroads.”Journal of the Transportation Research Forum 34, (1993): 70-85.

Braeutigam, R. "Learning About Transport Costs." J. Gomez-Ibanez, W.B. Tye and C. Winston, eds. Essays in Transportation Economics and Policy. Washington, D.C.: Brookings Institution Press (1999): Ch. 3.

Cefis, E. and O. Marsili. "A Matter of Life and Death: Innovation and Firm Survival." Industrial and Corporate Change 14, (2005): 1167-1192.

Dionne, G., R. Gagne, and C. Vanasse."Measuring Technical Change and Productivity Growth with Varying Output Qualities and Incomplete Panel Data." Journal of Econometrics 87, (1998): 303-327.

Fare, R., S. Grosskopf, M. Norris, and Z. Zhang. "Productivity Growth, Technical Progress and Efficiency Change in Industrialized Countries.” American Economic Review 84, (1994): 66-83.

Gallamore, R. "Regulation and Innovation: Lessons from the American Railroad Industry." J. Gomez-Ibanez, W.B. Tye, and C. Winston, eds. Essays in Transportation Economics and Policy. Washington, D.C.: Brookings Institution Press (1999): Ch. 15.

Lovell, C.A.K. Production Frontiers and Productive Efficiency. H.O. Fried, C.A. Lovell, and S.S. Schmidt, eds. The Measurement of Productive Efficiency: Techniques and Applications. New York, N.Y.: Oxford University Press (1993): Ch. 1. 
McMullen, B.S. and K. Okuyama. "Productivity Changes in the U.S. Motor Carrier Industry Following Deregulation: A Malmquist Index Approach.” International Journal of Transport Economics 27 (2000): 335-354.

Nix, F. "Trucking in Canada: A Profile." The Canadian Trucking Research Institute, Ottawa, Canada, 1996.

Nolan, J.F. "Productivity and Deregulation in the Canadian For-Hire Trucking Industry." 77th Annual Transportation Research Board (TRB) Conference, Washington, D.C., pre-print CD-ROM (1998).

Scherer, F.M. and D. Ross. Industrial Market Structure and Economic Performance, 3rd Ed. Houghton Mifflin Company, Boston, 1990.

Seiford, L. M. and R.M. Thrall. "Recent Developments in DEA: The Mathematical Programming Approach to Frontier Analysis." Journal of Econometrics 46, (1990): 7-38.

Shephard, R.W. Cost and Production Functions. Princeton University Press, Princeton, NJ, 1953.

Statistics Canada. Trucking in Canada. Transportation Division, Report \#53-222, Ottawa, 1993.

Transport Canada. Transportation in Canada: Annual Report. Ministry of Public Goods and Services, Ottawa, 1996.

Transport Canada. Transportation in Canada: Annual Report. Ministry of Public Goods and Services, Ottawa, 1999.

Viscusi, W.K., J. M. Vernon, and J. Harrington Jr. Economics of Regulation and Anti-Trust, 2nd Ed. MIT University Press, Cambridge, Mass., 1996.

Winston, C. "Economic Deregulation: Days of Reckoning for Microeconomists." Journal of Economic Literature 31, (1993): 1263-1289.

Wood, D. and J. Johnson. Contemporary Transportation, 5th Ed. Prentice Hall, Upper Saddle River, NJ, 1996.

Woudsma, C. G. and P.S. Kanaroglou."Deregulation of the Motor Carrier Industry: a Canadian Example.” Environment and Planning A 26, (1994): 343-360.

James Nolan is an associate professor in the Department of Bioresource, Policy, Business and Economics (formerly Agricultural Economics) at the University of Saskatchewan. James is currently developing a set of spatial and computational economic models for transportation and agricultural applications. In addition, James has been a co-editor for the Canadian Journal of Agricultural Economics since 2008.

Pamela Ritchie is professor and dean in the Faculty of Business and IT at the University of Ontario Institute of Technology in Oshawa. She received her Ph.D. in accounting and finance from Lancaster University. Her current research interests include transportation and logistics, financial and economic performance, and efficiency studies. 
Canadian For-Hire Trucking Industry

John Rowcroft was, until recently, professor of economics at the University of New Brunswick. He is currently an adjunct professor at the University of Ontario Institute of Technology in Oshawa. He received his Ph.D. in economics from Simon Fraser University. His current research interests include transportation and logistics, data envelopment analysis and the mathematical modelling of economic behaviour. 